\title{
Evaluation of the Carbowax Fixation and Embedding Method for the Oxidative Enzymes*
}

\author{
Ryuei Maeda, Reiko Takada, Ichiro Yamagata \\ and Tatsuji Hagihara \\ The First Department of Pathology (Prof. R. Maeda), \\ Kansai Medical School, Osaka, Japan
}

The authors have previously reported that the carbowx fixation and embedding procedure had demonstrated intense staining quality which provided a better localization in the field of histochemistry. The test, however, failed to show test for certain enzymes, i.e., Straus' test $^{\text {7) }}$ for succinic dehydrogenase and Gräff's test ${ }^{1)}$ for cytochrome oxidase. The purpose of present investigation is to attempt to modify the carbowax fixation and embedding method to demonstrate histochemically such oxidative enzymes which require unfixed freshness of sections.

\section{Materials and Methods}

For the tissues to be tested, the liver, kidney and adrenal of the Wistar rats were employed.

Procedures :

1) Immerse directly thin $(2-3 \mathrm{~mm}$.) slices of fresh tissues in carbowax 300 for 1 hour at $0-10^{\circ} \mathrm{C}$.

2) Transfer successively the tissue slices into carbowax $600 \mathrm{kept}$ at $25^{\circ} \mathrm{C}$. for 30 minutes.

3) Incubate the tissue slices in melted carbowax $1000 \mathrm{kept}$ at solidifying range $\left(38-40^{\circ} \mathrm{C}\right)$ and leave them for 15 minutes.

4) Transfer the tissue slices with carbowax into the embedding mold and solidifying them in a dessicator kept in a refrigerator.

5) Cut the carbowax tissue blocks into desired size and soak them in the paraffin oven kept at $50^{\circ} \mathrm{C}$.

6) Embed the carbowax tissue blocks with paraffin in a usual manner at a thickness of approximately $2 \mathrm{~mm}$. from the cutting surface of the carbowax blocks.

7) Cut sections $5-10 \mu$, if desired, by cold knife.

8) Float sections briefly on water, then spread over a glass slide.

For this revised method, the following histochemical techniques were adopted: Gräff's method ${ }^{11}$ for cytochrome oxidase, Nachlas et al. method ${ }^{\text {(s) }}$ for succinic dehydrogenase, Scarpelli et al. method $^{6)}$ for DPN diaphorase, Hess et al. method $^{2)}$ for DPN-linked diaphorase (lactic, malic, glutamic, $\alpha$-glyceropho-

* Aided by the Grant in Aid for Fundamental Scientific Research of the Ministry of Education 


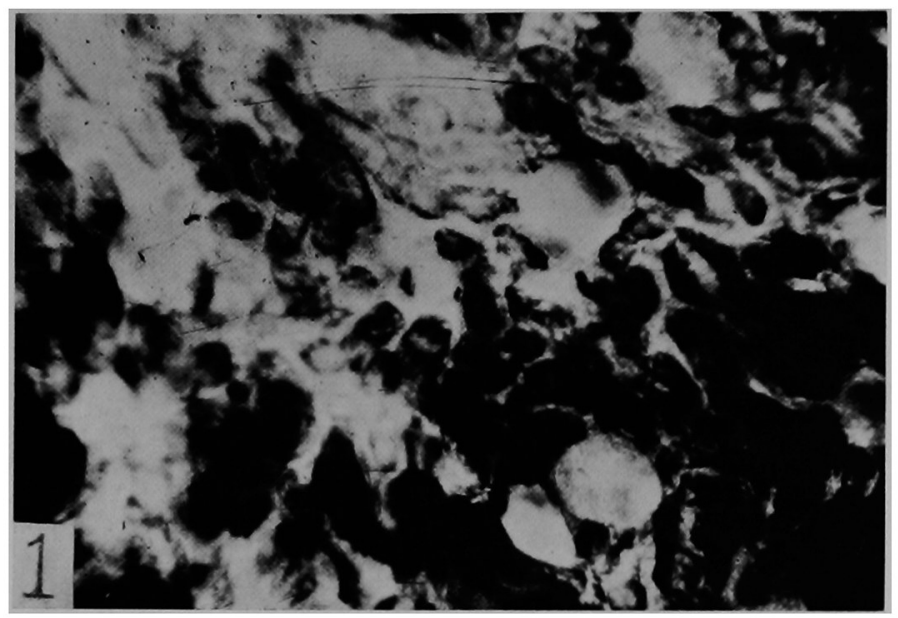

Fig. 1 Rat kidney treated with the carbowax fixing and embedding procedure; succinic dehydrogenase. The cytoplasm of cells of the convoluted tubules shows intense activity. No glomerular stainig is seen.

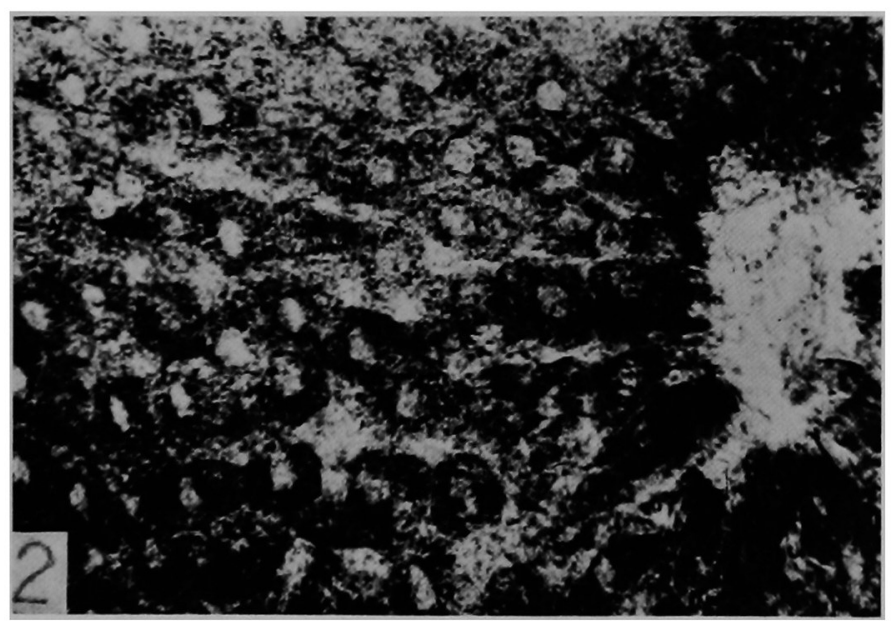

Fig. 2 Rat liver treated with the carbowax fixing and embedding procedure. Strong activity of DPN diaphorase is recognized in liver cells.

sphate and alcohol), Levy et al. modification ${ }^{3)}$ of Wattenberg's method ${ }^{8)}$ for steroid-3 $\beta$-ol dehydrogenase (dehydroepiandrosterone in the media was presented from Teikoku Zoki Co. Ltd.) and Hess et al. method ${ }^{2)}$ for TPN-linked dehydrogenase (isocitric and glucose-6-phosphate). The control staining without any substrate was used in every case in order to exclude the "nothing dehydrogenase." ${ }^{\text {9 }}$

\section{Results}

The revised method has proved to show a higher degree of positive reaction and the results were less dislocated compared with the cryostat technique ; 


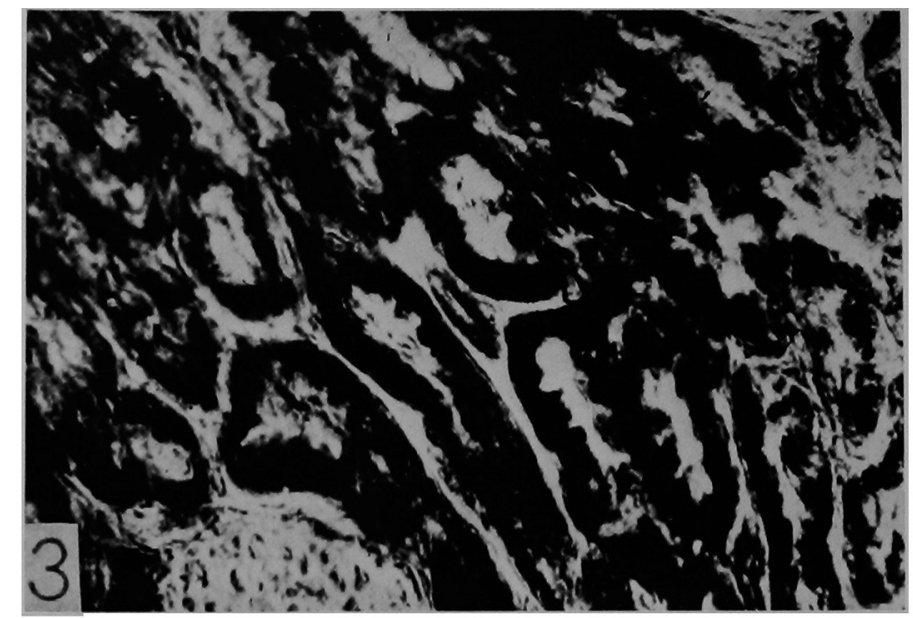

Fig. 3 Rat kidney treated with the carbowax fixing and embedding procedure. DPN diaphorase is intensely distributed in the tubular epithelium. Glomeruli are poorly stained.

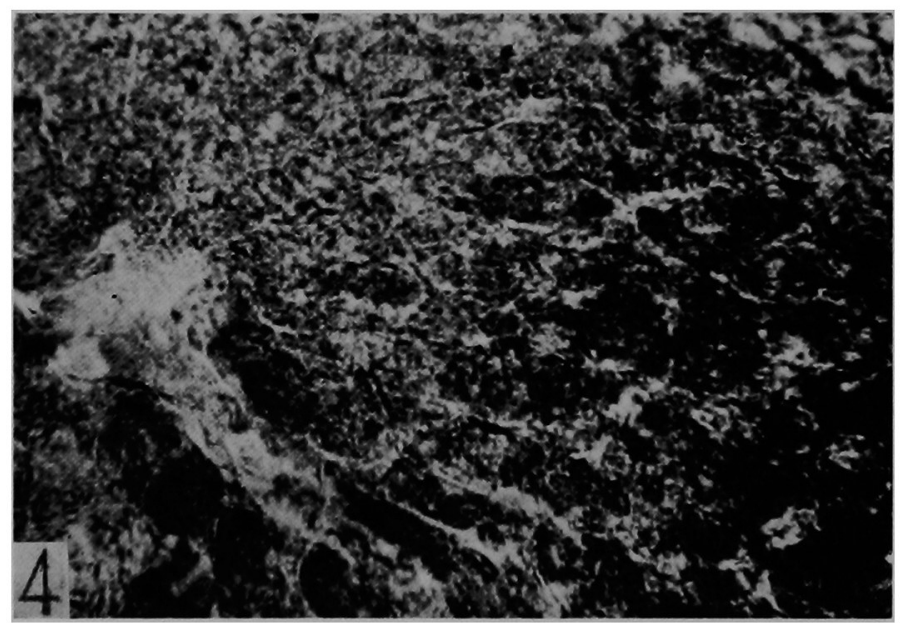

Fig. 4 Rat liver treated with the carbowax fixing and embedding procedure. TPN-linked isocitric dehydrogenase shows moderate activity in liver cells.

moreover, the method has an advantage of keeping the enzymatic activities of the carbowax tissue blocks at least for two months, avoiding diffusion of the formazan deposit produced in the sections.

It is desirable, however, the original method should be employed for detection of various substances which do not require necessarily use of the cryostat technique since the revision demands thorough technical training for the preparation of the sections.

\section{Discussion}

In our previous paper, it was reported that the method of carbowax fixation and embedding showed the negative results for some enzymes requiring fresh 
frozen section. Our subsequent investigation have revealed that negative results appear to be mainly due to the way of embedding with carbowax 4000 at temperature of $50^{\circ} \mathrm{C}$. Since solidifying range below the temperature of $40^{\circ} \mathrm{C}$. is suitable for preservation of the enzymatic activities in tissues, any kind above carbowax 1000 seemed to be unfit; hence present modification was based on the above reason.

\title{
Summary
}

The presen method with a revised carbowax fixation and embedding procedure has been proved to be most suitable especially for histochemical demonstration of the oxidative enzymes.

\section{References}

1) Gräff, S., Zbl. Path., 32, 337-341, $1922 . \quad$ 2) Hess, R., Scarpelli, D. G. and Pearse, A. G. E., J. Biophs. \& Biochem. Cytol., 4, 753-769, $1958 . \quad 3)$ Levy, H. Deane, H. W. and Rubin, B. L., Endocrinology, 65, 932-943, $1959 . \quad$ 4) Maeda, R., Morii, S., Kuwahara, I. and Takada, R., Acta Path. Jap., 10, 161-171,1960. 5) Nachlass, M. M., Tsou, K. -C., de Souza, E, Cheng, C. -S. ang Seligman, A. M., J. Histochem. \& Cytochem., 5, 420-436, 1957. 6) Scarpelli, D. G., Hess, R. and Pearse, A. G. E., J. Biophys. \& Biochem. Cytol., 4, 747-752, 1958. 7) Straus, F. H., Cheronis, N. D. and Straus, E., Science, 108, 113-115, 1948. 8) Wattenberg, L. W., J. Histochem. \& Cytochem., 6, 225-232, 1958.9 9) Zimmermann, H. and Pearse, A. G. E., J. Histochem. \& Cytochem., 7, 271-275, 1959.

\section{Histochemical Studies on Dehydrogenases in Free Cells Effects of fixation procedure on enzymatic activity.}

\author{
Keisuke Hikima and Akira Mizutani \\ Department of Pathology, Tuberculosis Research Institute, Kyoto University, \\ Kyoto (Director : Prof. Hideo TAKAMATSU)
}

Histochemical techniques for the demonstration of several dehydrogenases in free cells $(1,2,3,4)$ have recently been investigated using the tetrazolium salt 'Nitro-BT'. A number of investigators have employed Nitro-BT as an electron acceptor for histochemical studies of oxidative enzymes because of its superior properties, including high sensitivity to hydrogen and discrete intracellular localization of this compound $(5,6,7)$.

The use of unfixed cell smears is not desirable, since the diffusion of enzyme during incubation procedures and the non-specific staining $(8,9,10,11)$ may occur under these conditions. Quaglino and Hayhoe (2) demonstrated succinic dehydrogenase activity in blood and bone marrow cells which had been fixed in acetone prior to incubation. In this report, a variety of conditions for the 